\title{
Polyelectrolytes as Drug Carriers. Analysis by Dynamic Light Scattering of Reconstituted and in-situ Prepared Model Polymethacrylate-Drug Aqueous Dispersions
}

\author{
María C. Palena, Marina S. Ardusso, Ruben H. Manzo and Alvaro F. Jimenez-Kairuz*
}

Department of Pharmacy, Faculty of Chemical Sciences. Universidad Nacional de Córdoba - CONICET. Ciudad Universitaria, X5000HUA, Córdoba, Argentine

\begin{abstract}
This article reports dynamic light scattering (DLS) data, and electrokinetic $\zeta$-potentials of aqueous dispersions of two linear flexible polymethacrylic acid derivatives Eudragit ${ }^{\circledR}$ L100 (EuL) and S100 (EuS) loaded with two model drugs (D), lidocaine (Ld) and atenolol (At). Dispersions of EuL and EuS at 1,0\% neutralized with increasing percentages $(50,75$ and 100 mole $\%)$ of each $\mathrm{D}$ exhibited a unimodal scattering distribution rendering diffusion coefficients $(D C)$ in the interval of 4 to $9.10^{-9} \mathrm{~cm}^{2} / \mathrm{s}$. All dispersions $50 \%$ neutralized exhibited quite similar $D C$. However, the effect of increasing neutralization followed a different pattern in each Eudragit ${ }^{\circledR}$. All dispersions exhibited high negative $\zeta$-potentials that were lower at $100 \%$ with respect to $50 \%$ loading. Both, DC and $\zeta$-potentials, of redispersed lyophilized samples of (EuL-D) and (EuS-D) remained identical to those of in situ prepared while those of analog samples prepared by solvent evaporation exhibited some slight differences. The behavior of (EuL-D) and (EuS-D) systems examined here through DLS appears to be quite similar to that reported for polyelectrolytes neutralized with monovalent inorganic cations. Last, it has been shown that DLS provides valuable information about the reversibility from solid to dispersion states of these nanometric drug carrier systems.
\end{abstract}

Keywords: Polyelectrolyte-drug complexes, Eudragit ${ }^{\circledR}$ L100 and S100, nanoparticles, dynamic light scattering, nanometric drug carriers.

\section{INTRODUCTION}

The unique properties arising from the interaction of soluble polyelctrolytes (PE) with inorganic or organic counterions has been exploited for a variety of purposes such as taste masking [1], aqueous drug compatibility [2], drug stability improvement [3], viscosity building [4], metabolite trapping [5], drug delivery modulation [6-9], etc. In particular, in the field of drug delivery, polyelectrolite drug complexes (PE-D) are recognized as valuable drug carrirers [10].

Many (PE-D) stable aqueous dispersions may be easily prepared in situ through acid base reaction between the PE and an ionizable $\mathrm{D}$ counterion.

In fact, aqueous dispersions of PE having acid or basic pending groups react respectively with molecules having basic or acid groups, yielding a high proportion of counterionic condensation. Equation 1 depicts the reaction between the carboxylic groups of a $\mathrm{PE}\left(\mathrm{RCOO}^{-}\right)$with the basic groups of a drug D.

$\mathrm{R}-\mathrm{COOH}+\mathrm{D} \rightleftharpoons \mathrm{R}-\mathrm{COO}^{-}+\mathrm{DH}^{+} \rightleftharpoons \mathrm{R}^{-} \mathrm{COO}^{-} \mathrm{DH}^{+}(\mathbf{1})$

In the same way PE having protonable amino groups react with an acid group of a drug generating an analogue process of counterion condensation [11]. Fig. (1), shows a

*Address correspondence to this author at the Department of Pharmacy, Faculty of Chemical Sciences. Universidad Nacional de Córdoba - CONICET. Ciudad Universitaria, X5000HUA, Córdoba, Argentine; Tel: +54-3514334163; Fax: +54-351-4334127; E-mail: alvaro@fcq.unc.edu.ar representative set of species distribution of various (PE-D) dispersions [12].

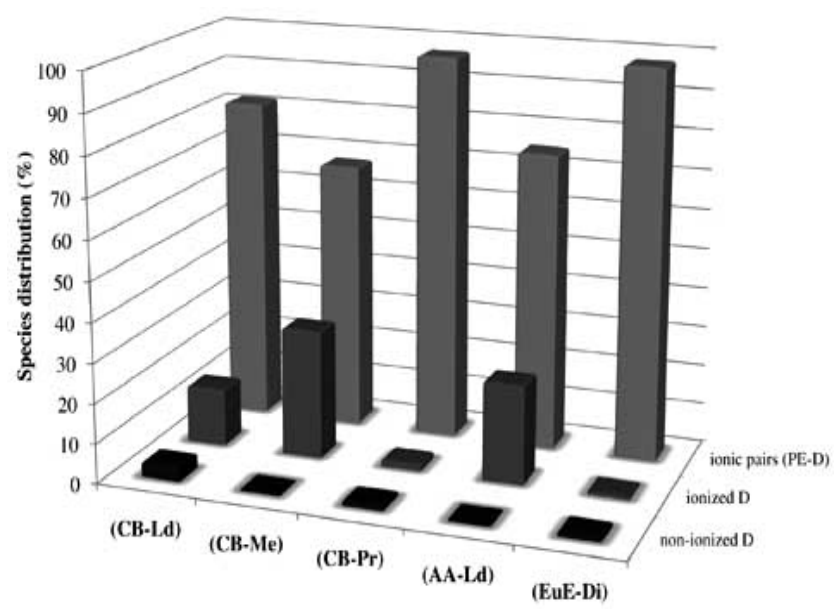

Fig. (1). Species distribution of different (PE-D) complexes. (CB: carbomer 934P; AA: alginic acid; EuE: eudragit ${ }^{\circledR}$ E100; Ld: lidocaine; Me: metoclopramide; $\mathrm{Pr}$ : procaine and Di: diclofenaco).

Besides, (PE-D) complexes may be obtained in solid state by solvent evaporation or lyophilization. Further dispersion in water of solid complexes generally yields aqueous systems having their original macroscopic properties like viscosity and degree of tansparency. This reversibility has 
Table 1. Relevant Physicochemical Properties of Model Drugs Used

\begin{tabular}{|c|c|c|c|c|c|}
\hline Drug & Molecular Structure & $\mathbf{p K a} \mathbf{a}^{(*)}$ & $M_{W}{ }^{(1)}$ & $\log P^{(* *)}$ & $S_{\text {app }}{ }^{(*)}(\mathrm{mg} / \mathrm{mL})$ \\
\hline Lidocaine & & 7.84 & 234.34 & 2.26 & 4 \\
\hline Atenolol & & 9.6 & 266.33 & 0.16 & 12.8 \\
\hline
\end{tabular}

Data taken from references ${ }^{(*)}[29,30]$ and ${ }^{(* *)}[31]$ (Log $\mathrm{P}=$ octanol/water partition coefficient).

been successfully used to design solid dosage forms based on (PE-D) complexes, i.e. swellable hydrophilic matrices [79].

The reversibility from solid state to aqueous dispersion it is not a common property of other drug carrier supramolecular aggregates or nano- and micro- particules, in which frequently different adjuvants or cryoprotectors are necessary in order to prevent irreversible physical changes.

The knowledge about the factors that determine the interactions between ionic or ionizable drugs and PE is relevant in the design of pharmaceutical dosage forms. At present a detailed description about the factors governing such interactions is not fully available. Therefore it is important to provide physical and chemical information on this field.

Thus, this article addresses an analysis by dynamic light sccattering (DLS) of a set of model (PE-D) aqueous dispersions focalized on the effect of increasing D loading on the $\mathrm{PE}$ and in getting more detailed information about the reversibility of (PE-D) complexes from solid state to aqueous dispersion. With that purpose two linear flexible polymethacrylic acid derivatives, Eudragit ${ }^{\circledR}$ (Eu) L100 and S100 of average molecular weight $\left(M_{W}\right)$ approx. 135,000 (Fig. 2) [13], were selected to be loaded in aqueous dispersions with two model D, lidocaine (Ld) and atenolol (At), whose structure and properties are reported in Table $\mathbf{1 .}$

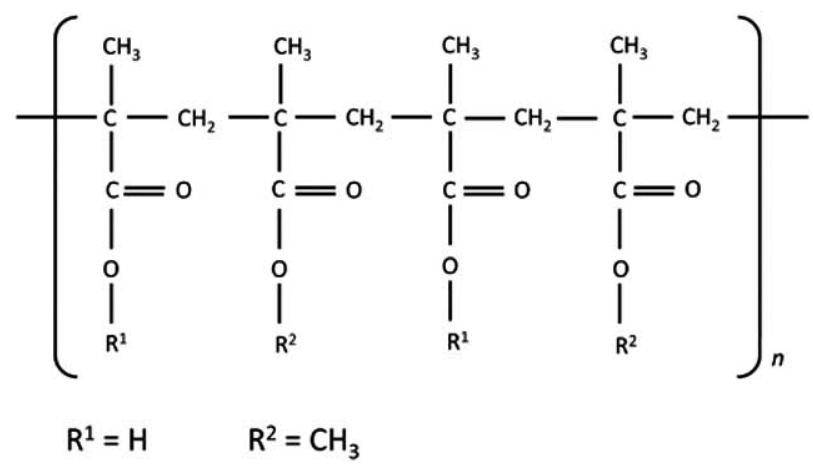

Fig. (2). Molecular structure of EuL and EuS. The ratio of free carboxyl groups to ester groups is approx. 1:1 in EuL and 1:2 in EuS and their average $M_{W}$ is approx. 135,000.
Ideally, if these dispersed macromolecular complexes would be completely expanded, they would be seen as a long rod of about $350 \mathrm{~nm}$ having a radius of $2-3 \mathrm{~nm}$ in those monomeric unities in which a D counterion is tightly associated with the acid group.

It is worth mentioning that at present DLS is currently used to characterize nanoparticles and self assembled structures in many fields like solid state chemistry [14-16], controlled drug delivery [17], toxicology [18], and environmental science [19] among others.

\section{MATERIALS AND METHODOLOGY}

\section{Materials}

The following materials were used: Eudragit $^{\circledR}$ L100 (EuL) and Eudragit ${ }^{\circledR}$ S100 (EuS) kindly supplied by Etilfarma S.A. Roehm $^{\circledR}$, Pharma-Polymers, Buenos Aires, Arg.). Atenolol (At) and lidocaine (Ld), both USP-grade (Parafarm ${ }^{\circledR}$, Bs.As., Arg.). Ethanol 96 (USP) (Porta Hnos., Córdoba, Arg.) and high quality water (Milli-Q water purification system, Millipore $\left.{ }^{\circledR}, \mathrm{MA}\right)$.

The carboxylic group content of each PE was assayed by acid-base titration with $\mathrm{NaOH} 0.1 \mathrm{~N}$ solution on exactly weighted samples of about $50 \mathrm{mg}$ dispersed in distilled water.

\section{Preparation of Dispersions}

The acid groups of aqueous dispersions of EuL and EuS at $1.0 \%$ were neutralized with 50,75 and 100 mole $\%$ of the model drugs, At or Ld. Each dispersion was prepared in a stoppered test tube by adding $10 \mathrm{ml}$ of water on exactly weighted amounts of Eu and D previously introduced. The mixture was subjected to mechanical agitation during $12 \mathrm{~h}$. Afterthat; the resulting dispersion was kept $24 \mathrm{~h}$ at room temperature before used.

Fifty percent neutralized dispersions (EuL-D) $)_{50}$ and $(\text { EuS-D })_{50}$ were appropriately diluted with water to get PE concentrations of 0.5 and $0.1 \%$.

Additionally, solid samples obtained either by solvent evaporation or lyophilization, were redispersed in the appropriate volume of water to get dispersions at $1.0 \%$ of each 


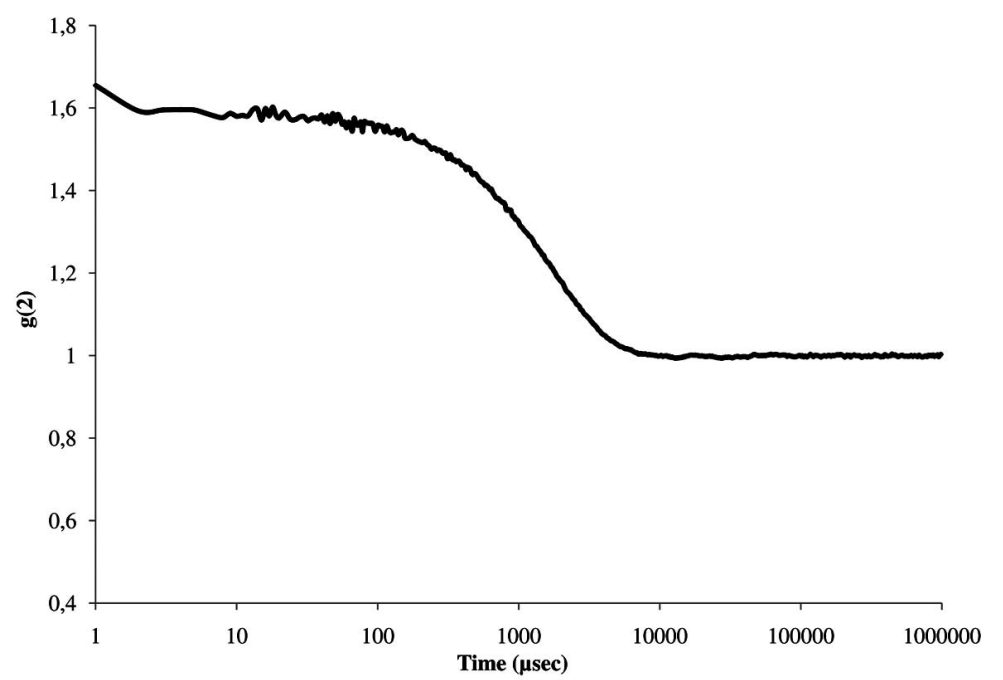

Fig. (3). Intensity autocorrelation function $g^{(2)}(\mathrm{t})$ for $(\text { EuL-Ld })_{50}$ aqueous dispersion at $1 \% \mathrm{w} / \mathrm{v}$ of EuL. Scattering angle $\theta=165^{\circ}$.

PE. The samples were added to the water as a fine powder under constant stirring for about $6 \mathrm{~h}$. After that, the resulting dispersion was kept $24 \mathrm{~h}$ at room temperature before used.

Three independent dispersions were prepared of each composition or procedure described in this section in order to get triplicate dynamic light scattering and electrokinetic $(\zeta-)$ potential measurements.

\section{Solid Complexes}

\section{Freeze-Drying}

Aqueous complex dispersions were freeze dried in glass vessels. The vessels were frozen at $-18{ }^{\circ} \mathrm{C}$ for $24 \mathrm{~h}$. After that, samples were lyophilized using a Labconco ${ }^{\circledR}$ Freeze Dry System/Freeze Zone 6, (Kansas City, MO, USA). The solid materials were removed after $24 \mathrm{~h}$ and stored at room temperature in tight containers.

\section{Solvent Evaporation Procedure}

Solid complexes were prepared by mixing in a mortar during 30 min appropriate quantities of each PE and D with sufficient volume of ethanol (about $20 \%$ ) to get a fluid mass. After that, the mixtures were dried at $45-50{ }^{\circ} \mathrm{C}$ until constant weight and milled to obtain fine powders that were stored at room temperature in tight containers.

\section{Dynamic Light Scattering and Electrokinetic Potential}

The diffusion coefficients $(D C)$ and $\zeta$-potential of aqueous dispersions were measured by dynamic light scattering (DLS) and Electrophoretic light scattering respectively, using Delsa Nano C instrument (Beckman Coulter, Osaka, Japan) equipped with a $658 \mathrm{~nm}$ laser diode, scattering angle of $165^{\circ}$ and temperature controller. Measurements were performed on triplicate at $25{ }^{\circ} \mathrm{C}$ allowing the instrument to automatically optimize signal intensity of the sample. The instrument software (DelsaNano 2.20, Beckman Coulter, Osaka, Japan), applying Smoluchowski equation, calculate the $\zeta$-potential of samples.

\section{RESULTS AND DISCUSSION}

Dinamic light scattering (DLS) data of (PE-D) $)_{x}$ were obtained with $1.0 \%$ aqueous dispersions of EuL and EuS neu- tralized with increasing percentages $(x=50,75$ and 100 mole \%) of the model drugs: At or Ld. Additionally, (EuD) 50 solid samples obtained by solvent evaporation or lyophilization, were redispersed in water and subjected to DLS analysis.

Diffusion coefficients $(D C)$ and hydrodynamic apparent diameters $\left(d_{H}\right)$ were obtained from the autocorrelation function $\left(g^{(2)}\right)$ provided by the software of the DLS equipment. Fig. (3) shows a representative plot of $g^{(2)}$ against time.

There are an important amount of reports dealing with dynamic and static light scattering of flexible linear PE with acid pending groups neutralized with monovalent inorganic cations (mainly $\mathrm{Na}^{+}$). Such systems exhibited a multimodal spectrum of relaxation times. In particular, two clearly differentiated diffusion modes were identified, one with $D C$ ranging from $10^{-7}$ to $10^{-5} \mathrm{~cm}^{2} / \mathrm{s}$, and the other ranging from $10^{-9}$ to $10^{-8} \mathrm{~cm}^{2} / \mathrm{s}$, which were regarded as "fast" $\left(D C_{f}\right)$ and "slow" $\left(D C_{s}\right)$ modes respectively [20,21].

Under the experimental conditions used in this work, only a unimodal distribution was observed rendering $D C$ in the interval of 4 to $9.10^{-9} \mathrm{~cm}^{2} / \mathrm{s}$, as reported in Table 2 . Therefore, the observed $D C$, clearly lie within the range of the slow mode early defined. Besides, the concentration dependence of the observed $D C_{s}$ (see Fig. 4) follows the same parttern early observed with PE neutralized with inorganic counterions [20]. This slow mode of diffusion has been associated to the presence of multichain domains (clusters) with dimensions appreciably exceeding the size of single chains. The $D C_{s}$ has been found in a wide variety of synthetic and biological polymers. Therefore, it appears that it is a universal property of charged macromolecules dispersed in polar solvents [20].

The origin of these domains as well as the mechanism by which macromolecules of like charge interact themselves are not satisfactorily understood [22-24].

The four $(\mathrm{Eu}-\mathrm{D})_{50}$ systems exhibited quite similar $D C_{s}$. However, the effect of increasing the degree of neutralization followed a different pattern in each Eudragit ${ }^{\circledR}$, as can be seen in Figs. (5a and 5b). 
Table 2. pH, Electrokinetic $\zeta$-potencial and Dynamic Light Scattering Data of $(\text { EuL-D })_{\mathrm{x}}$ and $(\text { EuS-D) })_{\mathrm{x}}$ Aqueous Dispersions at 1,0 \% of Eu

\begin{tabular}{|c|c|c|c|c|}
\hline$(\mathbf{E u}-\mathrm{D})_{\mathrm{x}}$ & $\mathbf{p H}$ & $\begin{array}{c}\text { DC } \\
\left(10^{9} \mathrm{~cm}^{2} / \mathrm{s}\right)\end{array}$ & $\begin{array}{c}\mathbf{d}_{\mathbf{H}} \\
(\mathbf{n m})\end{array}$ & $\begin{array}{c}\zeta \text {-potential } \\
(\mathbf{m V})\end{array}$ \\
\hline$(\text { EuL-Ld })_{50}$ & 7.09 & $4.7 \pm 0.2$ & $1041 \pm 37$ & $-22.9 \pm 0.7$ \\
\hline$(\text { EuL-Ld })_{75}$ & 6.72 & $8.0 \pm 2.6$ & $683 \pm 240$ & $-23.7 \pm 0.5$ \\
\hline$(\text { EuL-Ld })_{100}$ & 7.31 & $3.7 \pm 1.1$ & $1334 \pm 673$ & $-16.0 \pm 1.4$ \\
\hline$(\text { EuS-Ld })_{50}$ & 7.52 & $5.2 \pm 0.3$ & $940 \pm 48$ & $-25.4 \pm 2.7$ \\
\hline$(\text { EuS-Ld })_{75}$ & 7.45 & $3.9 \pm 0.1$ & $1248 \pm 39$ & $-23.2 \pm 1.1$ \\
\hline$(\text { EuS-Ld })_{100}$ & 7.50 & $3.9 \pm 0.7$ & $1313 \pm 257$ & $-21.1 \pm 0.7$ \\
\hline$(\text { EuL-At })_{50}$ & 6.55 & $5.2 \pm 0.3$ & $943 \pm 48$ & $-19.3 \pm 3.1$ \\
\hline$(\mathbf{E u L}-\mathbf{A t})_{75}$ & 6.80 & $6.9 \pm 0.2$ & $714 \pm 22$ & $-9.7 \pm 1.2$ \\
\hline$(\text { EuL-At })_{100}$ & 7.32 & $8.8 \pm 2.4$ & $597 \pm 174$ & $-11.7 \pm 2.3$ \\
\hline$(\text { EuS-At })_{50}$ & 7.36 & $5.0 \pm 0.4$ & $987 \pm 93$ & $-23.2 \pm 1.2$ \\
\hline$(\text { EuS-At })_{75}$ & 7.38 & $4.4 \pm 1.0$ & $1184 \pm 317$ & $-20.7 \pm 1.3$ \\
\hline$(\text { EuS-At })_{100}$ & 7.75 & $5.3 \pm 0.1$ & $927 \pm 8$ & $-17.5 \pm 1.5$ \\
\hline
\end{tabular}

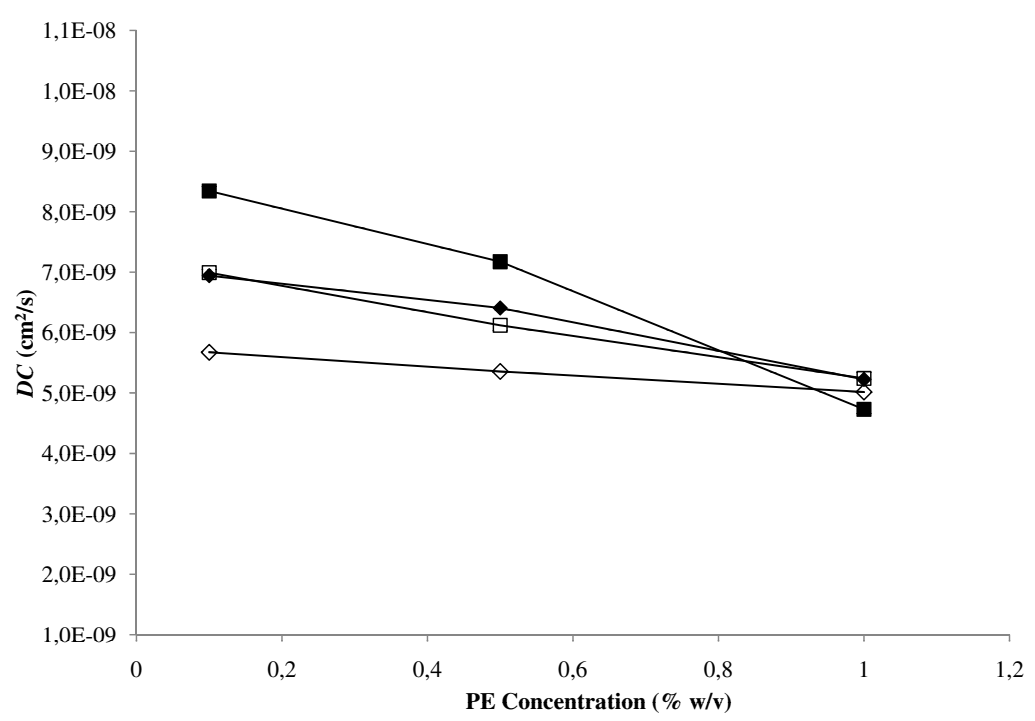

Fig. (4). Dependence of diffusion coefficient $\left(D C_{s}\right)$ on concentration $(\% w / v)$ of $(\text { EuL-At })_{50}(\diamond),(\text { EuL-Ld })_{50}(\boldsymbol{\square}),(\text { EuS-At })_{50}(\diamond)$ and $($ EuS$\operatorname{Ld})_{50}(\square)$.

In fact, $D C_{s}$ of (EuL-At) increased continuously from $\mathrm{x}$ $=50$ to $\mathrm{x}=100$ mole \%. However, $D C_{s}$ of $(\text { EuL-Ld })_{\mathrm{x}}$ although at $x=75$ was also higher than that at $x=50$, it decreased significantly at $\mathrm{x}=100$ mole $\%$. Therefore, the $d_{H}$ of (EuLLd) ${ }_{100}$ was twice times higher than that of (EuL-At) $)_{100}$ (see Table 2).

On the other hand, the increase of neutralization of EuS from 50 to 100 mole \% produced only a slight change on $D C_{s}$. In fact, $D C_{s}$ of $(\mathrm{EuS}-\mathrm{Ld})_{\mathrm{x}}$ exhibited a smooth modest decrease while that of $(\mathrm{EuS}-\mathrm{At})_{\mathrm{x}}$ remained almost constant.

In highly neutralized EuL complexes a high variability of results in the different samples assayed was observed.

Since charge interactions in PE dispersions dominantly influence the dynamics of light scattering, data on electroki- netic $\zeta$-potential are also reported in Figs. (6a and $\mathbf{6 b})$. All dispersions exhibited high negative $\zeta$-potentials and in all cases potentials of fully neutalized Eu were lower than those fifty percent neutralized.

Dispersions of EuS, exhibited a smooth linear decrease of $\zeta$-potentials with drug loading, which is in line with the modest changes of $D C_{s}$ observed. However, EuL did not exhibit a similar pattern, which is also in accordance with stronger changes in $D C_{s}$.

Within the framework of the counterion condensation theory of PE, a common point in the theoretical treatments proposed is the recognition of two extreme modes of counterion association with the PE, currently referred to as loose and covalent bonding. The former is the delocalized con- 

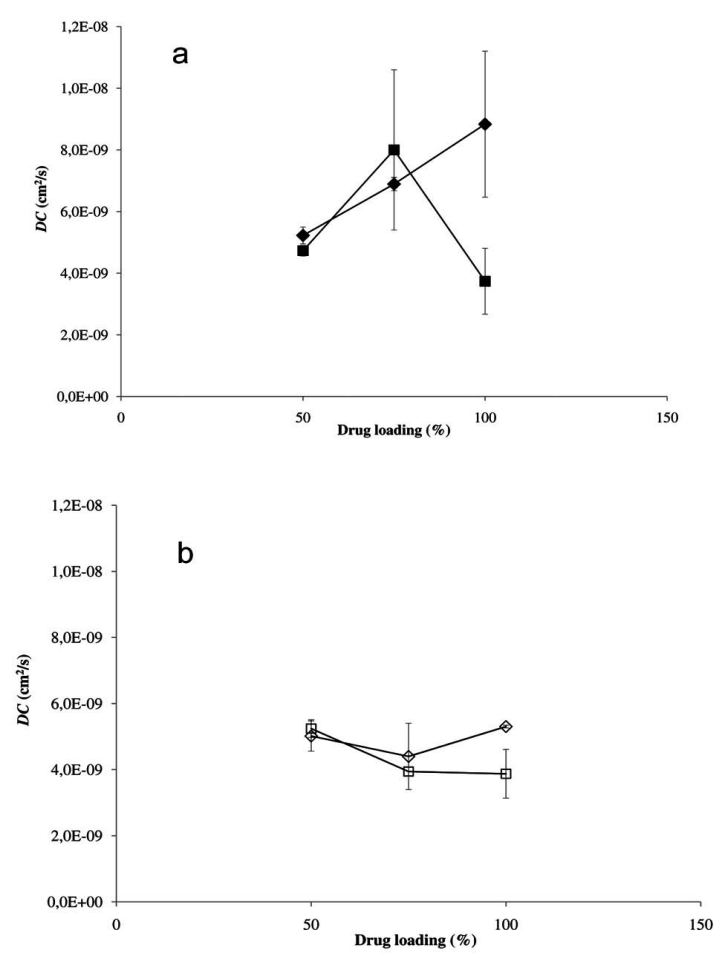

Fig. (5). Dependence of diffusion coefficient $(D C)$ on degree of neutralization of (a) EuL and (b) EuS with model drugs: (ם) Lidocaine and $(\diamond)$ Atenolol.

finement of the counterions within a condensation volume in the immediate vicinity of the PE, due only to long range interactions, while the latter is a short range, site specific interaction [25-27].

On the other hand, the fraction of $\mathrm{DH}^{+}$counterions that remains free in solution should be correlated with a concomitant fraction of ionized carboxylic groups $\mathrm{RCOO}^{-}$in the macroion. Therefore, the contribution of the macroion charges to $\zeta$-potentials should be maintained even at high drug loading. In relation to this point we have recently reported data on species distributions of EuL and EuS at1.0\% fifty percent neutralized with Ld (Table 3 ), in which the fractions of Ld condensed with the PE were 52.6 and 71.1 mole $\%$ respectively [28].

On the other hand, it has been reported that $D C_{s}$ of linear acid PE neutralized with inorganic counterions decreases slightly with the increase of the PE molecular weight. In this regard, it should be mentioned that the $M_{W}$ of random monomeric units of EuL and EuS are respectively 186 and
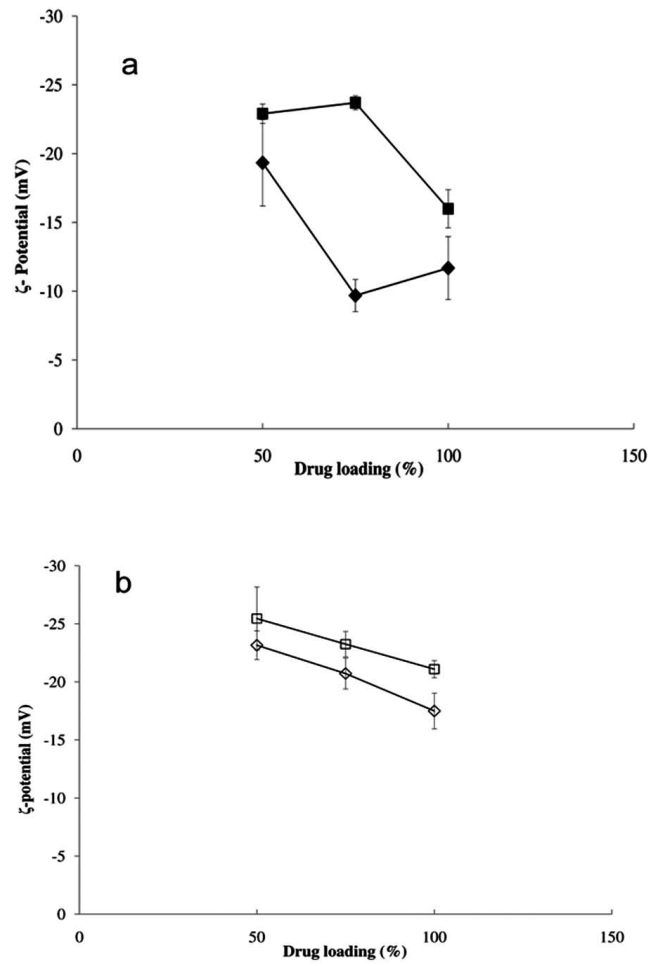

Fig. (6). Variation of -potential with the degree of neutralization of (a) EuL and (b) EuS with model drugs: (ם) Lidocaine and Atenolol.

256, while $M_{W}$ of $\mathrm{Ld}$ and At are respectively 234 and 266. Consequently, each condensed D counterion approximately duplicates the monomer $M_{W}$ and therefore drug loading increases significantly the original $M_{W}$ of the PE. For example, in the dispersions reported in Table 3 , the increase of $M_{W}$ due to the fraction of Ld condensed with PE is $162 \%$ and $144 \%$ for EuL- and EuS- complexes respectively. However, how much the loading effect would affect the $D C_{s}$ is a question outside the scope of the present results.

As lyophilized samples of (EuL-Ld $)_{50}$ and (EuL-At $)_{50}$ were redispersed both $D C_{s}$ and $\zeta$-potentials remained identical to those of dispersions prepared in situ (Figs. 7a and 7b). However, dispersions of analog solid samples prepared in ethanol (by solvent evaporation) exhibited some differences with those in situ prepared. In fact, $(\text { EuL-Ld) })_{50}$ although exhibited the same $D C_{s}$, its $\zeta$-potential was significantly lower, while $(\text { EuL-At })_{50}$ exhibited higher $D C_{s}$ and lower $\zeta$ potentials than those of in situ prepared dispersions.

Table 3. Stoichiometric Composition and Species Distribution of $(\text { EuL-Ld })_{x}$ and $(\text { EuS-Ld })_{x}$ in Aqueous Dispersions, at $1.0 \%$ of Eu, After the Partition with an Organic Solvent

\begin{tabular}{|c|c|c|c|c|c|c|}
\hline \multirow{2}{*}{ Dispersions $^{(1)}$} & \multirow{2}{*}{$\mathbf{p H}$} & \multicolumn{2}{|c|}{ Stoichiometric Composition } & \multicolumn{3}{|c|}{ Species Distribution ${ }^{(2)}(\%)$} \\
\cline { 3 - 7 } & & {$[\mathbf{E u}](\mathbf{e q} / \mathbf{L})$} & {$[\mathbf{L d}](\mathbf{M})$} & $(\mathbf{D})_{\mathrm{w}}$ & $\left(\mathbf{D H}^{+}\right)_{\mathrm{w}}$ & $\left(\mathbf{R C O O}^{-} \mathbf{D H}^{+}\right)_{\mathrm{w}}$ \\
\hline \hline$(\text { EuL-Ld })_{\mathbf{5 2 . 2}}$ & 6.50 & $4.85 \mathrm{E}^{-2}$ & $2.51 \mathrm{E}^{-2}$ & 1.76 & 45.60 & 52.64 \\
\hline$(\text { EuS-Ld })_{49.7}$ & 7.16 & $3.07 \mathrm{E}^{-2}$ & $1.54 \mathrm{E}^{-2}$ & 4.22 & 24.66 & 71.12 \\
\hline
\end{tabular}

${ }^{(1)}$ Species composition obtained after partition equilibrium with cyclohexane according with reference [7].

(2) Species distribution, expressed in \% of total drug remaining in the aqueous phase after partition equilibrium. 

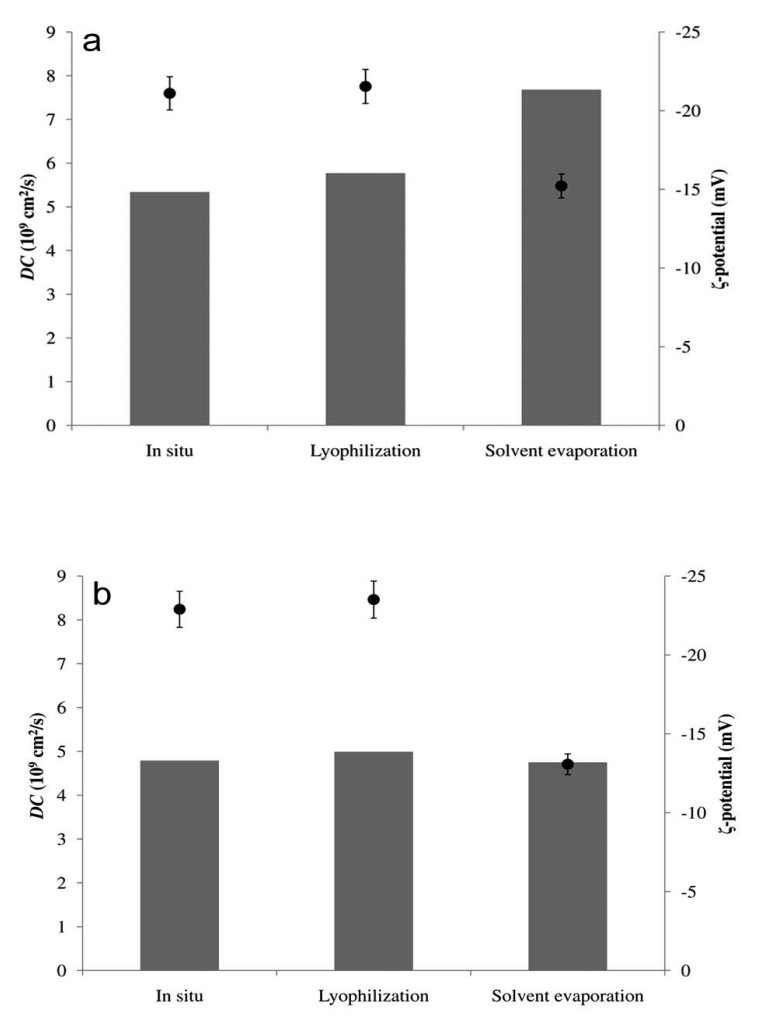

Fig. (7). Diffusion coefficients $\left(D C_{s}\right)$ (Columns) and -potential (O). (a) (EuL-At) $)_{50}$ and (b) (EuL-Ld) $)_{50}$ prepared by different procedures.

Recently, it was reported that changes in $D C_{s}$ produced by some stress applied on a PE dispersion (i.e. forced to pass through filter micropores) does not shift quickly to the early stage remaining relatively stable after the mechanical treatment [22]. Therefore, this would be the case with the samples prepared by solvent evaporation.

\section{CONCLUSIONS}

In general, the behavior of the (Eu-D) systems examined here through dynamic light scattering appears to be quite similar to that reported for PE and monovalent inorganic cations. However, the differences observed in the effect of D loading on "slow diffusion coefficient" among the (Eu-D) systems (i.e. between At and $\mathrm{Ld}$ in EuL and between EuL and $\mathrm{EuS}$ ) reveal the higher complexity of these systems. In fact, although the main contribution to the overall interaction arises from the electrostatic attraction, non-electrostatic contributions would also play a role in the association process as well as in the conformations of the chains. Therefore, systematic research with DLS together with electrokinetic potential on model (PE-D) systems would contribute to identify and rationalize such interactions. A more detailed structural description of these drug-carrier systems is relevant to understand their biopharmaceutical performance, which is associated with bioadhesivity and controlled release properties.

On the other hand, it has been shown that DLS provides valuable information about the reversibility from solid to dispersion states of these nanometric drug carrier systems, which is a desired property in the design of solid dosage pharmaceutical forms.

\section{ACKNOWLEDGEMENT}

Financial support from National Council of Scientific and Technological Research (CONICET, Arg.), FONCyT Préstamo BID 1201/OC-AR, and National University of Córdoba (SECyT-UNC), Córdoba, Arg., are greatly acknowledged. M.C. Palena and M.S. Ardusso thank CONICET for research fellowships. We would like to thank Etilfarma S.A. (Buenos Aires, Arg.) for the provision of Eudragit $^{\circledR}$ (L-100 and S-100). The authors thank Prof. M.E. Olivera for the manuscript revision.

\section{REFERENCES}

[1] Borodkin, S.; Sundberg, P. Polycarboxylic acid ion-exchange resin adsorbates for taste coverage in chewable tablets. J. Pharm. Sci., 1971, 60, 1523-1527.

[2] Vilches, AP.; Jimenez-Kairuz, AF.; Alovero, F.; Olivera, ME.; Allemandi, DA.; Manzo, RH. Release kinetics and up-take studies of model fluoroquinolones from carbomer hydrogels. Int. J. Pharm., 2002, 246, 17-24.

[3] Jimenez-Kairuz, AF.; Allemandi, DA.; Manzo, RH. The improvement of aqueous chemical stability of a model basic drug by ion pairing with acid groups of polyelectrolytes. Int. J. Pharm., 2004, 269,149-156.

[4] Billany, M. Suspensions and emulsions. Aulton, M.E., Ed.; In : Pharmaceutics. The Science of Dosage Form Design; Churchill Livingstone; London, 2002, pp. 340-342.

[5] Colestipol. In: Clinical Pharmacology; Gold Standard Multimedia. http://clinicalpharmacology.com/Forms/drugoptions.aspx?cpnum= $148 \& n=$ Colestipol. (accessed May 3, 2009).

[6] Jimenez-Kairuz, A.F.; Allemandi, D.A.; Manzo, R.H. Equilibrium properties and mechanism of kinetic release of metoclopramide from carbomer hydrogels. Int. J. Pharm., 2003, 250, 129-136.

[7] Jimenez-Kairuz, A.F.; Llabot, J.M.; Allemandi, D.A.; Manzo, R.H. Swellable drug-polyelectrolyte matrices (SDPM): characterization and delivery properties. Int. J. Pharm., 2005, 288, 87-99.

[8] Ramírez Rigo, M.V.; Allemandi, D.A.; Manzo, R.H. Swellable drug-polyelectrolyte matrices (SDPM) of alginic acid: characterization and delivery properties. Int. J. Pharm., 2006, 322, 36-43.

[9] Ramírez Rigo, MV.; Allemandi, DA.; Manzo, RH. Swellable drugpolyelectrolyte matrices of drug-carboxymethylcellulose complexes. Characterization and delivery properties. Drug Deliv., 2009, $16,108-115$.

[10] Koleng, J.J.; McGinity, J.W. Carbomer. Rowe, R.C.; Sheskey, P.J.; Owen, S.C., Eds. In: Handbook of Pharmaceutical Excipients; Pharmaceutical press and APhA: London; 2006, pp. 111-115.

[11] Quinteros, D.A.; Ramirez Rigo, M.V.; Jimenez-Kairuz, A.F.; Olivera, M.E.; Manzo, R.H.; Allemandi, D.A. Interaction between a cationic polymethacrylate (Eudragit E100) and anionic drugs. Eur. J. Pharm. Sci., 2008, 33,72-79.

[12] Jimenez-Kairuz A.F.; Ramirez Rigo, M.V.; Quinteros, D.; Vilches, A.P.; Olivera, M.E.; Alovero, F.; Manzo, R.H. Recientes contribuciones sobre la utilización de Polielectrolitos en sistemas portadores de fármacos. Parte I: Dispersiones Acuosas. Rev. Farm., 2008, 150(1),11-25.

[13] Eudragit $^{\circledR}$ L100 and S100, Specifications and test methods. Evonik Industries. http://www.pharma-polymers.com/pharmapolymers/ en/downloads/ (accessed Apr 7, 2009).

[14] Kockrick, E.; Schrage, C.; Grigas, A.; Geiger, D.; Kaskel, S. Syntesis and catalytic properties of microemulsions-derived cerium oxide nanoparticles. J. Solid State Chem., 2008, 181, 1614-1620.

[15] $\mathrm{Xu}, \mathrm{R}$. Progress in nanoparticles characterization: Sizing and zeta potential measurements. Particuology, 2008, 6,112-115.

[16] Hoo, C.M.; Starostin, N.; West, P.; Mecartney, M.L. A comparison of atomic force microscopy (AFM) and dynamic light scattering (DLS) methods to characterize nanoparticle size distributions. $J$. Nanopart. Res., 2008, 10, 89-96.

[17] Bootz, A.; Vogel, V.; Schubert, D.; Kreuter, J. Comparison of scanning electron microscopy, dynamic light scattering and analytical ultracentrifugation for the sizing of poly(butylcyanoacrylate) nanoparticles. Eur. J. Pharm. Biopharm., 2004, 57, 369-375.

[18] Kato, H.; Suzuki, M.; Fujika, K.; Horie, M.; Endoh, S.; Yoshida, Y.; Iwahashi, H.; Takahashi, K.; Nakamura, A.; Kinugasa, S. 
Reliable Size Determination of Nanoparticles Using Dynamic Light Scattering Method for in vitro Toxicology Assessment. Toxicol. In Vitro 2009, 23, 927-934.

[19] Chau, K.W. Investigation on effect of aggregate structure in water and wastewater treatment. Water Sci. Tech., 2004, 50(12), 119-124.

[20] Sedlák, M. Structure and dynamics of polylelectrolyte solutions by light scattering. Radeva, T., Ed.; In: Physical Chemistry of Polyelectrolytes; New York, Marcel Dekker Inc.; 2001, vol. 99, pp. 1-58

[21] Oosawa, F. Polyelectrolytes; New York, Marcel Dekker Inc.; 1997

[22] Sedlák, M. Mechanical properties and stability of multimacroion domains in polyelectrolyte solutions. J. Chem. Phys., 2002, 116(12), 5236-5245.

[23] Sedlák, M. Generation of multimacroion domains in polyelectrolyte solutions by change of ionic strength or $\mathrm{pH}$ (macroion charge). J. Chem. Phys., 2002, 116(12), 5256-5262.

[24] Sedlák, M. Real-time monitoring of the origination of multimacroion domains in a polyelectrolyte solution. J. Chem. Phys., 2005, 122(15), 151102-151103.

[25] Drifford, M.; Delsanti, M. Polyelectrolyte solutions with multivalent added salts: stability, structure, and dynamics. Radeva, T.; Ed.; Physical Chemistry of Polyelectrolytes; Surfactant science series: Marcel Dekker Inc.; 2001, vol. 99, pp. 135-161.
[26] Porasso, R.D.; Benegas, J.C.; Van den Hoop, H.; Paoletti, S. Chemical bonding of divalent counterions to linear polyelectrolytes: theorical treatment within the counterion condensation theory. Phys. Chem., 2001, 3, 1057-1062.

[27] Banegas, J.C.; Paoletti, S., A.G.T. van den Hoop, M. Affinity interactions in counterion-polyelectrolyte systems: competition between different counterions. Macromol. Theory Simul. 1999, 8, 61-64.

[28] Ardusso, MS.; Manzo, R.H.; Jimenez-Kairuz, A.F. Comparative study of three structurally related acid polyelectrolytes as carriers of basic drugs: Carbomer, Eudragit L100 and S100. Supramol. Chem., (in Press: GSCH-447343; Dec, $2^{\text {nd }} 2009 ; 00(0): 1-9$ ).

[29] Powell, M. Lidocaine and Lidocaine Hydrochloride. Florey, K., Ed.; In: Analytical Profiles of Drug Substances; Academic Press; 1986, vol. 15, pp. 761-777.

[30] Caplar, V.; Mikotic-Mihun, Z.; Hofman, H.; Kuftinec, J.; Kajfez, F. Atenolol. Florey, K., Ed.; In; Analytical Profiles of Drug Subtances; Academic Press; 1984, vol. 13, pp. 1-25.

[31] Hansh, C.; Leo, A.; Hoekman, D. Exploring QSAR: hydrophobic, electronic, and steric constants. ACS Professional Reference Book; 1995.

(C) Palena et al.; Licensee Bentham Open.

This is an open access article licensed under the terms of the Creative Commons Attribution Non-Commercial License (http://creativecommons.org/licenses/by-nc/3.0/) which permits unrestricted, non-commercial use, distribution and reproduction in any medium, provided the work is properly cited. 